\title{
Biochemically silent pheochromocytoma - rare, but not uncommon. Case study
}

\author{
Marta Soltysiak', Piotr Gołofit ${ }^{2}$, Marek tokaj ${ }^{3}$ Jacek Glowala', Krystyna Widecka' \\ ${ }^{1}$ Department of Hypertension and Internal Diseases, Pomeranian Medical University, Szczecin, Poland \\ ${ }^{2}$ Department of Diagnostic and Intervention Radiology, Pomeranian Medical University, Szczecin, Poland \\ ${ }^{3}$ Plastic, Endocrine and General Surgery Clinic, Pomeranian Medical University, Szczecin, Poland
}

\section{Summary}

Approximately 5-6.5\% of adrenal incidentalomas are pheochromocytomas, and $8 \%$ of the patients with a pheochromocytoma are completely asymptomatic. Marker-negative pheochromocytomas represent a small group of rare tumours, yet rarely reported in the current medical literature. In the current study presents a case of 49-year old patient with hypertension, caused by biochemically silent pheochromocytoma and the potential medical complications, which can be particularly dangerous in cases of misdiagnosed, non-functional tumours.

key words: pheochromocytoma, biochemically silent pheochromocytoma, secondary hypertension

Arterial Hypertens. 2015, vol. 19, no. 4, pages: 200-202

DOI: $10.5603 / A H .2015 .0025$

\section{Case report}

49-year-old patient with paroxysmal hypertension complicated by grade I/II hypertensive retinopathy was admitted to Department of Hypertensiology due to episodes of high blood pressure (BP) accompanied by severe headache, sweating, pale skin of the face, and tremor. Three months prior to current hospitalization, patient had a CT scan of abdomen which revealed right adrenal tumour classified as incidentaloma. At the time of examination, BP was 130/ $187 \mathrm{~mm} \mathrm{Hg}$ and heart rate $68 / \mathrm{min}$. Physical examination showed a systolic murmur with maximal loudness on the left edge of the sternum. Standard electrocardiography and heart ultrasonography were normal. Laboratory tests revealed mild normocytic anaemia and hypercholesterolemia. Plasma renin activity and aldosterone level (in the basal conditions and after administration of $2.0 \mathrm{~L}$ of saline) were normal. Similarly, metanephrine excretion values in 24-hour urine collection, repeated four times, were within normal ranges. Baseline clinical and biochemical characteristics are shown in Table I. In 24-hour Ambulatory Blood Pressure Monitoring (ABPM), mean BP was $131 / 82 \mathrm{~mm} \mathrm{Hg}$ (range from $104 / 65 \mathrm{~mm} \mathrm{Hg}$ to $198 / 106 \mathrm{~mm} \mathrm{Hg}$ ) (Figure 1). Angio-CT of the abdomen revealed a nodular mass in the right adrenal gland with density of 44/95/74 HU and the absolute washout rate of $41.2 \%$ which ruled out the diagnosis of adenoma (Figure 2). Metaiodobenzylguanidine scintigraphy (MIBG) showed area of excessive tracer accumulation in the right adrenal gland, suggesting pheochromocytoma (Figure 3). During hospitalization, several acute episodes of hypertension associated with headache, pallor of skin, sweating, anxiety, and hyperglycaemia were observed.

Address for correspondence: lek. Marta Sołtysiak Klinika Hipertensjologii i Chorób Wewnętrznych SPSK 1 PUM ul. Unii Lubelskiej 1, 71-252 Szczecin tel.: (91) 4253550 faks: (91) 4253552 e-mail: marta.soltysiak00@gmail.com 
Table I. Baseline clinical and biochemical characteristics

\begin{tabular}{l|c}
\hline Clinical parameters & Value \\
\hline Systolic blood pressure [mm Hg] & 131 \\
\hline Diastolic blood pressure [mm Hg] & 82 \\
\hline Mean arterial pressure [mm Hg] & 98.3 \\
\hline Height [cm] & 174 \\
\hline Weight [kg] & 71 \\
\hline Body mass index [kg/m²] & 23.4 \\
\hline Biochemical parameters & \\
\hline Plasma cortisol AT 8:00 AM [ug/dL] & 12.9 \\
\hline Plasma cortisol after 1mg of Dexa- & 0.64 \\
methasone [ug/dL] & \\
\hline Plasma Androstenedione [ng/mL] & 0.48 \\
\hline Plasma Aldosterone & 63 \\
\hline Plasma Renin Activity & 1.03 \\
\hline 24-hour urine metanephrines & $48-58-48-94$ \\
\hline [mg/24h]
\end{tabular}

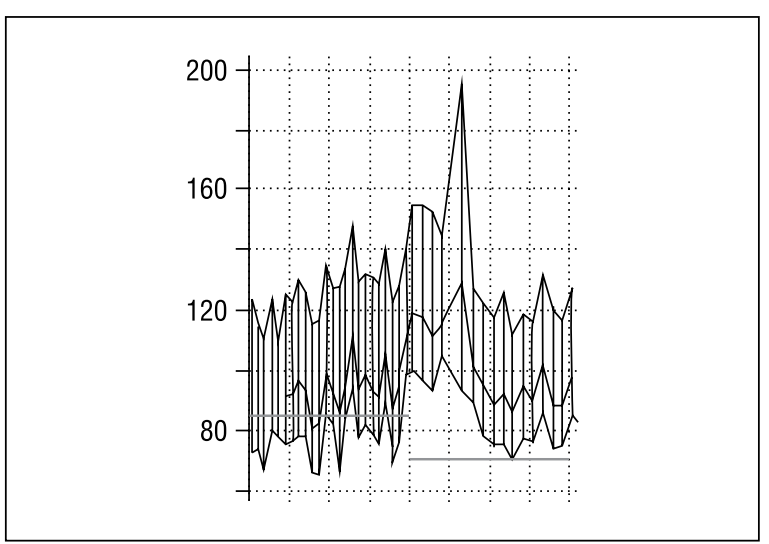

Figure 1. The result of 24-hour Ambulatory Blood Pressure Monitoring

Patient was referred to surgery unit with diagnosis of pheochromocytoma. Before surgical procedure, patient received a 2-week treatment with alpha and beta blockers, according to current recommendations and clinical guidelines [1]. During surgical removal of right adrenal gland, hypertensive episode requiring administration of phentolamine occurred. Histopathological examination confirmed pheochromocytoma.

\section{Discussion}

Approximately 5-6.5\% of adrenal incidentalomas are pheochromocytomas, and $8 \%$ of the patients with a pheochromocytoma are completely asymptomatic and usually have a familial form [2]. The sensitivity of the 24-hour urinary metanephrines

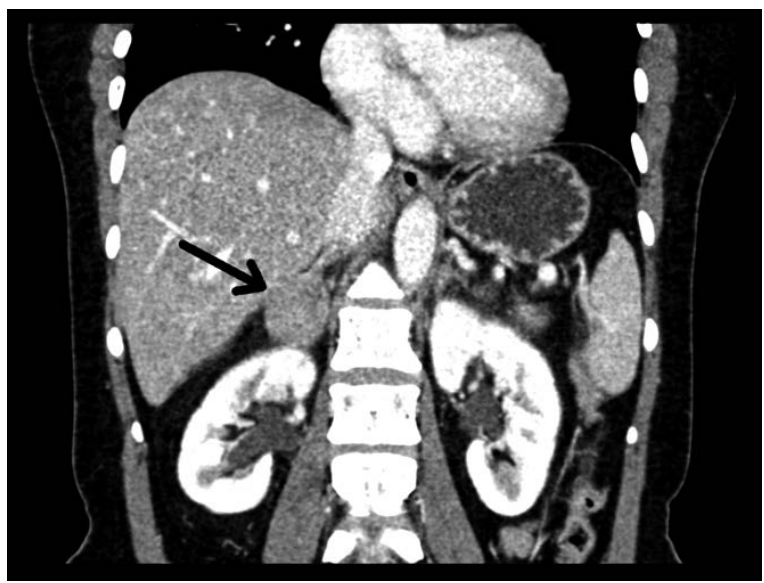

Figure 2. CT scan (Courtesy of Professor Anna Walecka, PMU 2015)

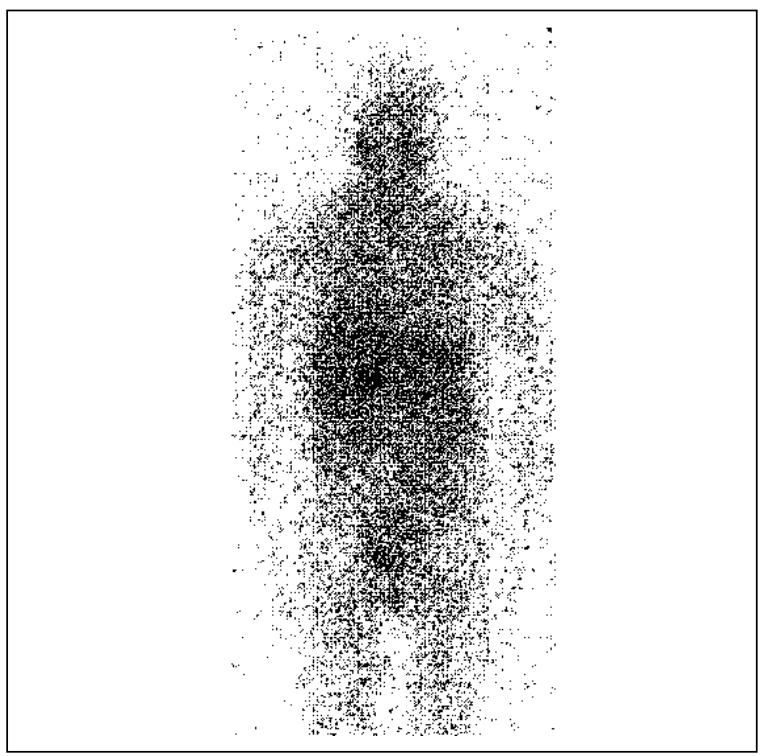

Figure 3. MIBG Scintigraphy

collection in the diagnosis of pheochromocytoma has been reported to $98 \%$ [3]. Marker-negative pheochromocytomas represent a small group of rare tumours [4]. In spite of the fact that there is a little information in the current literature on the prevalence of marker-negative pheochromocytomas, the existence of these cases has been established [2, 5-8]. Vanderveen et al. examined a group of 20 patients with pheochromocytomas and paragangliomas, where two of them were biochemical negative [9]. Timmers et al. have reported a biochemically silent abdominal paragangliomas in 4 patients with a mutation in the succinate dehydrogenase subunit B (SDHB) gene [10]. Literature data indicate a relationship between the size of pheochromocytoma and its biochemical activity and identify cases of clinically and biochemically asymptomatic tumours with sizes 
less than $1 \mathrm{~cm}$ [11-13]. Several studies explored the associations between BMI and metanephrines levels, indicating a higher incidence of obesity in marker-negative patients with pheochromocytoma [2].

In this case, the patient had a larger tumour mass, typical clinical symptoms, BMI and the concentration of metanephrine in 24-hour urine collection within the normal range. Thus, the diagnostic value of this test is not absolute. Literature suggests several possible reasons for these findings: the presence of a smaller piece of functional tissue, the release of a small amount of unmetabolized catecholamines due to a rapid intratumoural turnover rate, episodically secreting tumours, silent stress-activated tumours, and false negative results due to the high-temperature handling of the laboratory specimen and an ingestion of caffeine 24 hours prior to the testing [2].

Our patient suffered a hypertensive episode during adrenalectomy. This case demonstrates the potential complications of surgical intervention, which can be particularly dangerous in cases of misdiagnosed, non-functional tumours, as demonstrated by Heavner M. et al. [14].

In conclusion, among patients with adrenal incidentalomas, biochemically negative pheochromocytomas are rare, but not uncommon [14]. Episodic course of hypertension in patients with adrenal tumours, even with normal biochemical test results, should obligate to suspect the pheochromocytoma and expand the diagnostics accordingly.

\section{References}

1. Tykarski A., Narkiewicz K., Gaciong Z. et al. Guidelines for the Management of Hypertension. Arterial Hypertens. 2015; 3: 101-119.

2. Kota S.K., Kota S.K, Panda S. et al. Pheochromocytoma: An uncommon presentation of an asymptomatic and biochemically silent adrenal incidentaloma. Malaysian J. Med. Sci. 2012; 19: 86-91.

3. Van Berkel A., Lenders J.W., Timmers H.J.: diagnosis of endocrine disease: Biochemical diagnosis of phaeochromocytoma and paraganglioma. Eur. J. Endocrinol. 2014; 170: 109-119.

4. Lenders J.W., Pacak K., Eisenhofer G. New advances in the biochemical diagnosis of pheochromocytoma: Moving Beyond catecholamines. Ann. NY Acad Sci. 2002; 970: 29-40.

5. Mantero F., Terzolo M., Arnaldi G. et al. A survey on adrenal incidentaloma in Italy. J Clin Endocrinol Metab. 2000; 85: 637-644.

6. Ozkaya M., Yuzbasioglu M.F., Bulbuloglu E. et al:: Incidental pheochromocytoma presenting with sublaboratory findings in asymptomatic surrenal masses: a case report. Cases J. 2008; $1: 10$.

7. Lee J., Zarnegar R., Shen W. et al. Adrenal incidentaloma, borderline elevations of urine or plasma metanephrine levels, and the ,subclinical" pheochromocytoma. Arch. Surg. 2007; 142: 870-873.

8. Eisenhofer G., Peitzsch M. Laboratory evaluation of pheochromocytoma and paraganglioma. Clin. Chem. 2014; 60: 1486-1499.

9. Vanderveen K., Thompson S., Callstrom M. et al. Biopsy of pheochromocytomas and paragangliomas: Potential for disaster. Surgery 2009; 146: 1158-1166.

10. Timmers H., Pacak K., Huynh T. et al. Biochemically silent abdominal paragangliomas in patients with mutations in the succinate dehydrogenase subunit B gene. J. Clin. Endocrinol. Metab. 2008; 93: 4826-4832.

11. Blake M., Krishnamoorthy S., Boland G. et al. Low-density pheochromocytoma on CT: A mimicker of adrenal adenoma. AJR Am. J. Roentgenol. 2003; 181: 1663-1668.

12. Stenstrom G., Waldenstrom J.: Positive correlation between urinary execretion of catecholamine metabolites and tumor mass in pheochromocytoma. Result in patients with sustained and paroxysmal hypertension and multiple endocrine neoplasia. Acta Med. Scand. 1985; 217: 73-77.

13. Eisenhofer G., Lenders J., Goldstein D. et al. Pheochromocytoma catecholamine phenotypes and prediction of tumor size and location by use of plasma free metanephrines. Clin. Chem. 2005; 51: 735-744.

14. Heavner M., Krane L., Winters S. et al. Pheochromocytoma diagnosed pathologically with previous negative serum markers. J. Surg. Oncol. 2015; 112: 492-495. 